\title{
The Use of Islamic Patterned Art Therapy: Healing of Psychological Problems Among University Students
}

\author{
Bibi Hajra $^{1} \cdot$ Tamkeen Saleem $^{1}$ (D)
}

Accepted: 15 March 2021 / Published online: 15 April 2021

(c) The Author(s), under exclusive licence to Springer Science+Business Media, LLC, part of Springer Nature 2021

\begin{abstract}
This study was designed to adopt art therapy from an Islamic perspective by adding/including shapes and designs of Islamic origin. This was basically color therapy and was designed to find its effectiveness in reducing depression, anxiety. Stress and enhancing psychological well-being of university students with high and lowreligious levels from Islamabad and Rawalpindi. This study was carried out in two phases. The first phase was to develop Islamic adult coloring book with Islamic patterns and calligraphy. The second phase was the main study, and it was an experimental study which included screening out a sample, consisting of mild to moderate levels of depression, anxiety and stress and high and low-religiosity levels. A sample of 60 university students received Islamic patterned art therapy. On the basis of religiosity, two groups were formed as either a high-religious group or a low-religious group with individuals in both groups completing fourteen sessions. Pre- and post-test assessments were undertaken via the psychometric tools DASS-21, psychological well-being scale and religiosity scale. Statistics from the independent sample t-test and paired sample t-test and repeated measures ANOVA for within group and between group comparisons, revealed that there was a significant difference from pre-test to post-test assessments of depression anxiety and stress and psychological well-being, whereas there were nonsignificant gender differences on the bases of high and low-religiosity levels. Therefore, it could be concluded that Islamic patterned art therapy was found effective in reducing depression anxiety stress and increasing psychological well-being of university students.
\end{abstract}

Keywords Islamic integrated art therapy $\cdot$ Depression $\cdot$ Anxiety $\cdot$ Stress · Religiosity $\cdot$ Psychological well-being

Tamkeen Saleem

tamkeen.saleem@iiu.edu.pk

Bibi Hajra

sparklinghajra24@gmail.com

1 Department of Psychology, International Islamic University, Islamabad, Pakistan 


\section{Introduction}

Living with psychological problems is a major issue which impairs daily, occupational and academic functioning, and lowers psychological well-being in general. University students specifically fall prey to anxiety and stress due to academic stress, family problems, social disturbances, etcetera. Anxiety, stress and depression can have a negative impact on their lives and well-being. In the present era, attending college and university places a great deal of stress as student juggle coursework, assignments, quizzes, career concerns along with social and family issues and the pressures that influence their social and academic life (Hunt and Esinberg 2010). Previously, students were totally dependent on their parents, but with the passage of time and need, students are now working part time jobs to support themselves. A study conducted by Mounsey et al. (2013) stated that working students showed up to endure from more trouble related to feelings, social working, mental well-being and need of vitality.

Psychological issues like depression, anxiety and stress contribute to the overall psychological well-being of an individual. In other words, psychological well-being of students is greatly influenced by the presence of depression, anxiety and stress. Religion has a great significance that how religious people have a chance to suffer from these psychological problems and how religiosity helps in overcoming them.

Religiosity can be characterized as convictions, sentiments and practices are tied to religion (Ho and Ho, 2007). It is important to decrease depression, anxiety and stress level in a nonthreatening way among students through well-evidenced approach, which is art therapy. Religion and otherworldly existence have numerous components that are of potential pertinence to mental well-being, counting devout participation, private devout exercises (e.g. supplication and pursuing of Sacred texts), a feeling of association or relationship with God, devout convictions and devout adapting. In expansion, religion and spirituality may cause mental well-being by means of solid ways of life and practices and advancement of social support (Cohen \& Koenig, 2003).

Art therapy is widely used for treating psychological problems and disorders. Its evidence-based approach for studying psychological problems and different studies has proven its effectiveness for various psychological problems. Art therapy is based on the thought that the creative process of craftsmanship is mending and life upgrading. It is a type of nonverbal communication of contemplations and sentiments. This therapy is progressively utilized by therapist with people of all age groups and with a diverse range of populations. Not as it was only used by therapists, it could be used by counselors, psychologists, doctors, teachers and social workers are utilizing the expression of emotions in the form of art for mending and treatment (Malchiodi, 2003). Art therapy methods include drawing, coloring, collage making, photography, clay modeling, etc. Making art can reduce stress and one does not even need to have artistic skills (Boucher, 2016). A study reported that ladies experience internal changes as sudden, unforeseen turning point or as more progressive process and art therapy may help to alter within the sense of moving from an insufficient to a more beneficial state (Holmqvist et al. 2016). 
Art is as old as human civilization. Art can be traced from pre-historic time and was of great significance till date. There is a special place of art in every culture and civilization and religion. Art is the symbolic representation of any community. With the spread of the Islam, in seventh century, the particular style of Islamic art progressively established utilized primarily for religious architecture, book outlines, and the enrichment of ceramics, metal products and other valuable objects. Islamic art was affected by the creative styles of the victorious over areas. These encompass the Roman, Byzantine and Persian art.

Islamic art is affected by two religious restrictions by the teachings of prophet Muhammad (PBUH), i.e., not to copy God who is the ultimate creator of everything, drawing images of living things termed as "Aniconism." Discouraged the use of expensive material. That is why Islamic artists basically work with wood, clay and brass (Bosch, 2015). This prohibition of drawing humanly or living beings is mentioned in multiple hadith, one of which is as follows:

Ibn Abbas (May Allah be pleased with him) reported:

I heard the messenger of Allah saying

"Every painter will go to hell, and for every portrait he has made, there will be appointed one who will chastise him in Hell." Ibn Abbas said: If you have to do it, draw pictures of trees and other inanimate things (Modudi, 1983).

However, some of the Islamic scholars are of different view about Aniconism. They say that the Holy Quran clearly forbid the representation of human figures; it simply condemns adulation.

The most fundamental design components of Islamic art include calligraphy or art of writing that is decorative and symbolic way of transmitting Allah's message to the people. Foliate or vegetal symbolism in which clear out, vines and other plants are rendered in enriching ways is also prominent. Geometric designs are greatly used in Islamic art. Most designs are created with grid of polygons such as equilateral triangles, squares or hexagons. The numerical terms for these frameworks is "regular tessellation" in which one standard polygon rehashed to tile the plane. Most geometric decorations are made on the preface that each design could be rehashed and infinity expanded into space. Symmetry is made in Islamic geometric patterns through the repetition and reflection of one or more fundamental design-units often shapes like circles and polygons. In spite of the fact that the design can be expounded and made complex, the fundamental symmetrical reiteration and reflecting to their shapes make a sense of harmony (Henry, 2015).

Coloring books and coloring pages for adults have been introduced recently that has proved be amazingly restorative and can offer assistance in producing wellness, quietness, mindfulness and the precise same benefits which reflection confers on the brain.. There are different types of adult coloring books, but the well-known coloring pages are that of mandalas for adults. Mandalas are symmetrical patterns and are originated from Buddhism. Coloring is like meditation and benefits of coloring for adults are; help in de-stress, reduction in anxiety, help adults re-discover themselves, help adults reconnect with their inner child and overall relaxation (Olesen, 2018). 
The present research aims to develop adult Islamic coloring book and then using it as a therapeutic intervention for the reduction of depression, anxiety and stress. It will also be used in increasing the psychological well-being among university students. A large research gap with specific reference to Pakistan is present on art therapy and specifically coloring the figures permissible in Islam as an intervention has not been studied. This research is proposed to study this therapeutic intervention in our own social milieu of university. Globally work has been done on coloring mandalas as a therapeutic intervention with different mental disorders like anxiety (Mehmood et al. 2017), depression (Gussak, 2007), stress (Boucher, 2016), PTSD (Chapman et al. 2011), child abuse (Pifalo 2006) and so on. A study conducted in Pakistan indicates that Mandala coloring as a therapeutic technique is beneficial in reducing anxiety which in turn can enhance work outcome and improve quality of life (Mehmood et al. 2017).

In another study conducted by Hussain and Khalily (2015), it is stated that art making is a mental ventilation with the help of which people learn self-coping skills. It further argues that art helps people to manage their psychiatric problems, improve functioning and coping with life stresses effectively. This present study aims to explore effectiveness of the Islamic patterned art therapy in the reduction of depression, anxiety and stress and enhancement of psychological well-being among university students.

Islamic aniconism is criticized a lot by west but with the use of geometric shapes and figures permissible in Islam, for the present study a unique Islamic adult coloring book will be developed by incorporating coloring Islamic art patterns and calligraphy i.e. patterns and free-hand calligraphy may reduce psychological problems, namely depression, anxiety and stress, and increase the level of psychological wellbeing of people. Different Islamic scholars see aniconism differently based on their cultures, brought up, being educated in western institutes, religious orientation and racial orientations. All of them shape up their view of Islamic aniconism (Soganci 2004). A study conducted by Khan (2012) states that the unbounded conceivable outcomes of inventive expression, inside art therapy, are so tremendous that indeed within the non-appearance of metaphorical representation, one can still get advantage from the method of results of art therapy.

Muslim clients feel reluctant to color the animal figures available for coloring and sometimes report it to be unislamic. This research will address the criticism of aniconism when used with Muslim clients or by Muslim therapists. It will also put forward the implications for art therapy that may be used within Muslim practice. The present study proposes that the interface between psychology and religion has helpful suggestions for the restorative work of specialists and that counseling psychology has been especially persuasive in driving the way toward a more prominent intrigued on the part of clinicians within the nature and purpose of religious experience by centering instep of the marvel of spirituality (Michael et al. 2007).

This will help to promote art therapy in Islamic perspective. This prohibition of drawing humanly or living figures leads to the development of a unique art designs in Islam which are unique and are considered to be the core of Islamic art and architecture. It will address the criticism of aniconism when art therapy used with Muslim clients or by Muslim therapists. It will put forward the implications for 
art therapy that may be used within Muslim practice. It will also spread awareness about the color therapy and how to overcome psychological problems and enhance psychological well-being. This therapeutic intervention is not only limited to students and adults, but can be used for the illiterate and handicapped and for people of all age groups. It can be used as a self-help technique or as a helping tool in various settings such as academic, clinical and work to help overcome depression, anxiety and stress and hence improve psychological well-being.

\section{Objectives}

The objectives of the study are as follows.

1. To develop adult coloring book with figures of Islamic art for university students.

2. To measure the levels of depression, anxiety and stress among the university students.

3. To study the effectiveness of Islamic art therapy for the reduction in depression, anxiety and stress and increase in psychological well-being among university students.

4. To compare the post-test levels of depression, anxiety, stress and psychological well-being between individuals with high and low levels of religiosity.

\section{Method}

\section{Research Design}

The present study was based on a pre-test post-test experimental design, and it comprised of two phases.

\section{Phase I}

It comprised of the development of Islamic adult coloring book. Recommendations were taken from the experts for each selected pattern, and the pattern with highest rates by the experts was included for Islamic adult coloring book. (20 patterns and 1 free-hand calligraphy).

\section{Phase II}

It included the use of Islamic patterns of art as an intervention for the reduction of depression, anxiety and stress and increase of psychological well-being. It included two-week intervention; daily coloring of one art pattern. Pre-test measures were taken for depression, anxiety and stress and psychological well-being with depression anxiety and stress scale (DASS), Ryff psychological well-being scale (PWS) and religiosity scale than two-week intervention of daily coloring of one art pattern 
was given to the study participants; post-test measures were taken. The mediums used were pencil colors.

\section{Sample}

This study was a quasi-experimental study that included a pre-/post-test design for the present study. The sample size was calculated through WHO sample size calculator. A purposive sample of 60 university students with age range of 18 to 30 years (BS and Masters Program students) was drawn after initial screening from universities of Islamabad and Rawalpindi, (International Islamic university Islamabad, University of Wah, COMSATS and Quaid-e-Azam University). Two groups were formed on the basis of initial screening of the level of religiosity i.e. low religiosity $(n=30)$ and high religiosity $(n=30)$.

\section{Inclusion Criteria}

For the present study, following inclusion criteria were used to recruit participants of the study. Individuals were capable to respond to the questions of the questionnaires and willing to participate, having mild to moderate level of scores on depression, anxiety and stress. Participants having severe level were not included and were referred to psychiatric clinic services for complete treatment. Similarly, individuals who had experienced schizophrenia spectrum or related disorders in past, using psychotropic drugs, or other psychological treatments since past 6 months, diagnosed with risk of committing suicide or any other mental disorder as well as dementia and brain injury were not included. Also the students of art and architecture fell in exclusion criteria of the present study because these students being involved in art-related activities keep them under academic pressure.

\section{Instruments}

Following instruments were used for the present study:

\section{Baseline Screening Sheet}

This included the information as if the subject was willing to participate, was Muslim or not, falls in the specific age range or not, taking any psychological treatment, diagnosed with any psychological illness, having any neurological problem and most importantly on their score on the religiosity scale.

\section{Demographic Sheet}

Each participant's personal details (e.g., age, gender, education, educational institute, CGPA, marital status, taking any psychological consultation, any medication, psychological or physical illness.) were collected. 


\section{Depression Anxiety Stress Scale (DASS-21)}

Depression anxiety and stress scale (DASS) developed by Lovibond and Lovibond in 1995. It contains three subscales, namely depression, anxiety and stress. Each subscale of DASS has 7 items and uses 4-point severity or frequency scales to assess the degree to which participants have undergone depression, anxiety and stress during the past week. Score for each individual subscale was calculated by making a sum of the scores on each item as marked by the participant. The Cronbach alpha reliability of the scale is as under according to a study by Jeff and Paul (2010), depression $\alpha 0.97$, anxiety $\alpha 0.92$ and stress $\alpha 0.95$.

\section{Ryff Psychological Well-Being Scale}

It comprises of 42-items and provides score on all six areas of the scale. The scale provides scores on subscales for each concept; overall, it measures psychological well-being (Ryff, 1995). For present study, composite score was used. The items are responded as 1 to 6 , for all 42 items. The possible range of scores is from 6 to 252. A high score represents a person with higher psychological well-being. The Cronbach alpha reliability of the scale ranges from 0.66 to 0.79 .

\section{Religiosity Scale}

It has total of 5 items, all are reverse scored. It is five-point Likert type scale in which $1=$ strongly agree and $5=$ strongly disagree. Score ranges from 5 to 25 for the scale (Wilkes and Howell, 1986). Higher scores indicate higher level of religiosity and have Cronbach alpha reliability of 0.91 (Anil, 2012).

\section{Procedure}

The current study basically pertains to provide art therapy to those who experience symptoms of depression, anxiety and stress. Art therapy was adopted with figures and shapes with reference to Islamic art. Adult Islamic coloring book was developed based on the patterns used in Islamic art, and different patterns were included on the basis of the recommendations of the experts. The first phase of the study comprised of the development of coloring book and for that purpose different designs and art patterns were selected from different mosques, buildings and calligraphy. All the designs were first reproduced/developed and made a total of 37 designs comprising of arabesques, calligraphy and tessellations. Five experts included three from psychology department, two from Islamic art and architecture department and one expert from Arabic department (expertise in calligraphy) rated the art patterns.

On the basis of the expert's ratings, 20 designs were retained with one freehand calligraphy. Participants could chose 13 designs out of 20 to color, and on the last days of therapy, they had to do free-hand calligraphy as a 14th design 
ending the therapy. For calligraphy, chisel tip black marker was provided because as per calligraphy rules chisel tip is a suitable choice for beginners.

After the development of the coloring book, the institutional authorities were approached for approval of data collection. Individual participants were approached. Informed consent was taken from the participants before data collection. The data were collected from students from International Islamic university Islamabad, COMSATS, University Of Wah and Quaid-e-Azam University. Art therapy was carried out in the psychology clinic/medical centers of the above stated institutes, daily session comprised of 30-45 min for each participant of the two groups. The conditions of the room in which the therapy was conducted were regulated in order for the subject to feel comfortable while coloring Islamic adult coloring book. The environment of the room was free from distractions, and all the phones were put on silent. The seating was also comfortable enough for the subject to do coloring. Last but not the least, the room was well-lit and had moderate temperature.

Initially, 87 participants were selected as a sample when screening was carried out on the bases of mild to moderate levels of depression, anxiety and stress. Twenty-seven participants were discarded on the bases of the severity levels of above stated variables leaving behind a total of 60 participants as a study sample. However, they were referred to psychological services centers for provision of treatment. Another criterion of the study was to have two equal groups of 30 participants having high and low religiosity which was assessed on the religiosity scale. Those subjects were retained who scored high or low on religiosity scale so out of 87,60 participants fulfilled that criterion on this scale after screening (Fig. 1).

A two-weeks intervention of Islamic art as an intervention therapy for the reduction of depression, anxiety and stress and increase of psychological well-being was

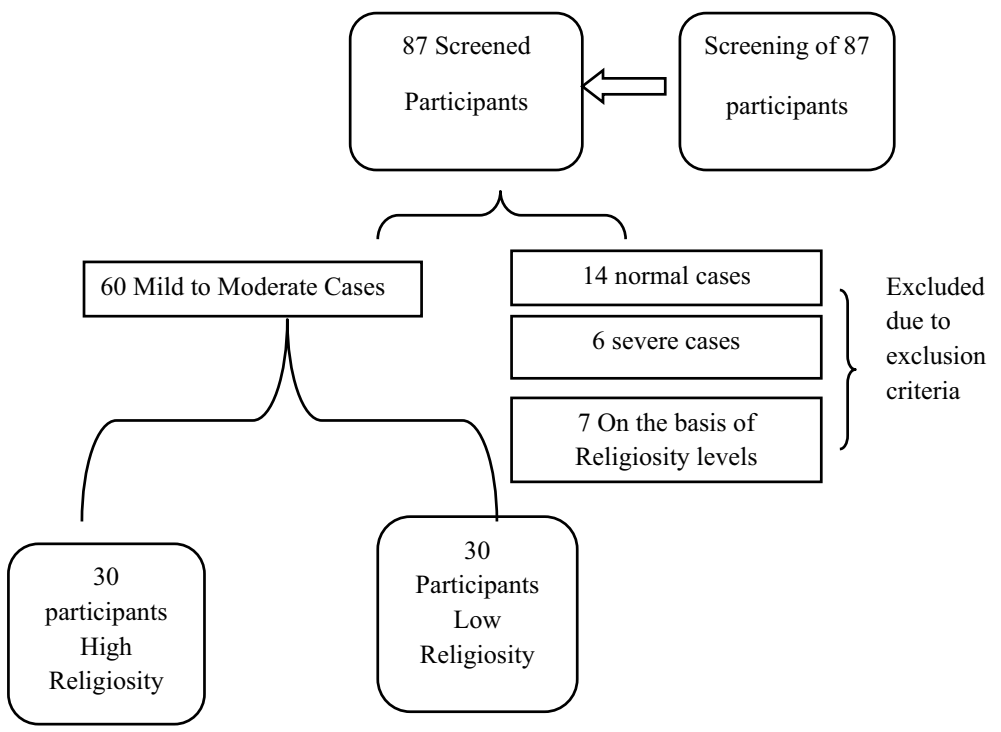

Fig. 1 Sample Selection Flowchart 
planned. Before giving intervention, participants were screened on screening sheet which was based on the information as if the subject was willing to participate, was Muslim or not, falls in the specific age range or not, taking any psychological treatment, diagnosed with any psychological illness, having any neurological problem and most importantly on their score on the religiosity scale.

Pretest assessments were taken for depression, anxiety and stress scale (DASS21), Ryff psychological well-being scale (PWS-42) and Religiosity measure scale; then, two-week intervention of daily coloring of one art pattern was given to the study participants. On the last day of therapy, participants were asked to do freehand calligraphy. Post-test measures were taken (by research assistant) to compare the scores also at the end they were thanked for their cooperation. The mediums used were pencil colors (a set of 12 colors).

\section{Session Plan for Islamic Integrated Art Therapy}

Therapy comprised of fourteen individual sessions. The time duration for completion of all the therapy sessions was two weeks. Individual therapy sessions were given to the clients. On average, one therapy session lasted for no more than $30 \mathrm{~min}$ duration. An understanding of the proceedings of therapy sessions is provided in outline given below.

Session 1 The first session was initially based on rapport building and psycho-education about the procedure of therapy and its use as a treatment for dealing with depression, anxiety, stress and one's psychological well-being. Informed consent was taken from the study subjects. Study protocols were explained. Timings were informed. Each session was for 30-45 min. Baseline screening was carried out with the help of screening sheet, and pretest assessments were taken for depression, anxiety and stress scale (DASS-21), Ryff psychological well-being scale and religiosity scale.

Session 2-13 After every therapy session participants were asked to discuss their experience regarding the color therapy. Participants were inquired if they had any questions. Their queries were answered promptly and with full dedication. Record of the subjective feelings of the participants was kept after they were done with color therapy for every session. Reaction time and total time were noted for each session before and after the color therapy.

Session 14-Termination In last session, all participants were asked to do free-hand calligraphy. As in previous all sessions study, subjects had to carry out color therapy in the given designs or art patterns so to find out that what would be their subjective feelings if they could do calligraphy themselves, was planned. After doing calligraphy, a record of subjective feelings was kept, and then, post-test assessments were taken. As this was also the termination of the therapy, participants were asked that how did they feel after undergoing Islamic integrated art therapy and most of them reported that they found this therapy very effective for the reduction of their psychological issues and felt relaxed, calmed and stress free after it. 


\section{Follow-Up}

In order to assess the effectiveness of the treatment modalities, a follow-up was conducted after three months. Yet, due to non-availability of the participants due to Pandemic of Covid-19, the follow-up was conducted in the form of a feedback in order of obtaining the data on the psychological status of the participants. Some of the participants were not accessible; therefore, only $63 \%$ of the data was accessed and a feedback as verbatim was taken. Concerned authorities of the relevant universities were contacted in order to seek permission for data collection. Therapeutic plan included 14 individual sessions, where each session lasted for 30 min duration on average. These 14 sessions were completed in 2-week duration. It also included one session of $45 \mathrm{~min}$, out of which $30 \mathrm{~min}$ were specified for daily coloring a designed pattern.

\section{Ethical Consideration}

Participants provided with the information, purpose of the study and informed consent were taken, if they would like to undergo this therapy. The participant's informed consent was secured and anonymity was guaranteed to them. Participation was voluntary and they were informed that they can quit the therapy at any point in time and there was no penalty for it. Participants were addressed about the fact that their identity and information will always be safe and will only be used for the purpose of research. In case of any adverse event, it was reported and recorded and was recommended for other therapeutic or medical aid. Measures were taken to control the biases in the research. Pre-trial bias was controlled by setting inclusion/exclusion criteria and by controlled randomization of participants through an unbiased research assistant. Interviewer bias was controlled by getting the pre-assessment of participants done by some other member (Research Assistant) not by examiner. Performance bias was controlled by following the pre-defined protocol of therapy for all participants. Post-trial bias was controlled by getting the post-assessment of participants done by some other member not by examiner.

\section{Results}

The results of the study were analyzed for Phase I and Phase II.

\section{Results of Phase I}

The first phase of the study comprised of the development of coloring book and for that purpose different designs and art patterns were selected from different mosques, buildings and calligraphy. All the designs were first reproduced/developed and made a total of 37 designs comprising of arabesques, calligraphy and tessellations. Five experts included three from psychology department, two from Islamic art and 
architecture department and one expert from Arabic department (expertise in calligraphy) rated the art patterns. On the bases of the expert's ratings, 20 designs were retained with one free-hand calligraphy. Participants could chose 13 designs out of 20 to color, and on the last days of therapy, they had to do free-hand calligraphy as a 14th design ending the therapy. For calligraphy, chisel tip black marker was provided because as per calligraphy rules chisel tip is a suitable choice for beginners.

Later on a try out three students from IIUI were first screened on the baselines, and then, Islamic coloring booklets were provided to them with colored pencils. Reaction time and total tie of coloring were noted. A two-week intervention was carried out, and in the end, participants were reassessed on psychological tools like DASS and Ryff psychological well-being scale. Results showed a significant difference on pre- and post-test assessments. It was also noted if they had any objection or reluctance for any design which was not found.

\section{Results of Phase II}

Table 1 shows frequency and percentage with respect to gender, age, education, educational institute, CGPA, marital status and family background. The overall sample consisted of greater number of females than males. Data were categorized into three

Table 1 Descriptive statistics of all variables of study for the levels of religiosity, i.e., high religiosity $(n=30)$, low religiosity $(n=30)$ and total sample $(N=60)$

\begin{tabular}{|c|c|c|c|c|c|c|c|}
\hline & & \multicolumn{2}{|c|}{$\begin{array}{l}\text { High religios- } \\
\text { ity }\end{array}$} & \multicolumn{2}{|c|}{ Low religiosity } & \multicolumn{2}{|c|}{ Total sample } \\
\hline & & $f$ & $\%$ & $f$ & $\%$ & $f$ & $\%$ \\
\hline \multirow[t]{2}{*}{ Gender } & Male & 7 & 23.3 & 16 & 53.3 & 23 & 38.3 \\
\hline & Female & 23 & 76.7 & 14 & 46.7 & 37 & 61.7 \\
\hline \multirow[t]{3}{*}{ Age } & $18-21$ & 18 & 60 & 21 & 70.0 & 39 & 65.0 \\
\hline & $22-25$ & 9 & 30 & 7 & 23.3 & 16 & 26.7 \\
\hline & $26-30$ & 3 & 10 & 2 & 6.7 & 5 & 8.3 \\
\hline \multirow[t]{3}{*}{ Education } & BS & 14 & 46.7 & 18 & 60.0 & 32 & 53.3 \\
\hline & M.sc & 8 & 26.7 & 1 & 3.3 & 9 & 15.0 \\
\hline & MS & 8 & 26.7 & 11 & 36.7 & 19 & 31.7 \\
\hline \multirow[t]{4}{*}{ Educational institute } & IIUI & 11 & 36.7 & 9 & 30.0 & 20 & 33.3 \\
\hline & COMSATS & 5 & 16.7 & 3 & 10.0 & 8 & 13.3 \\
\hline & University of Wah & 8 & 26.7 & 11 & 36.7 & 19 & 31.7 \\
\hline & Quaid-e-Azam university & 6 & 20 & 7 & 23.3 & 13 & 21.7 \\
\hline \multirow[t]{2}{*}{ CGPA } & $2-2.9$ & 3 & 10 & 0 & 0 & 3 & 5.0 \\
\hline & $3-4$ & 27 & 90 & 30 & 100.0 & 57 & 95.0 \\
\hline \multirow[t]{2}{*}{ Marital status } & Single & 22 & 73.3 & 28 & 93.3 & 50 & 83.3 \\
\hline & Married & 8 & 26.7 & 2 & 6.7 & 10 & 16.7 \\
\hline \multirow[t]{2}{*}{ Family background } & Nuclear & 17 & 56.7 & 11 & 36.7 & 28 & 46.7 \\
\hline & Joint & 13 & 43.3 & 19 & 63.3 & 32 & 53.3 \\
\hline
\end{tabular}


age groups. Majority of participants fell in age range 18 years to 21 years. On the basis of education level, participants were categorized in three groups. Majority of participants had BS level education. On the basis of educational institutes, most of the students were from IIUI and the CGPA was categorized and mostly participants fell in 3-4 CGPA categories. Similarly, single participants were greater in number in the overall sample after analyzing marital status. On the bases of family system, sample was categorized into two levels, i.e., nuclear and joint family system. It is evident from the results that there was less difference between the two levels, but joint family system was, however, greater than nuclear family system.

Table 1 also shows frequency and percentage with respect to gender, age, education, educational institute, CGPA, marital status and family background for both high and low levels of religiosity. The high religiosity level consisted of greater number of females than males whereas level of low religiosity consisted of greater number of males than females. Majority of participants fell in age range 18 years to 21 years for both the levels of religiosity. On the basis of education level, participants were categorized in three groups. Majority of participants had bachelors BS level education in both groups. On the basis of educational institutes, most of the students were from IIUI in high-religious group, whereas majority of the participants were from Uni of Wah in low-religious group. CGPA was categorized and mostly participants from both the groups fell in 3-4 CGPA category. Similarly, single participants were greater in number in the both groups after analyzing marital status. On the bases of family system, sample was categorized into two levels, i.e., nuclear and joint family system. It is evident from the results that in high-religious group, nuclear family system was greater, whereas in low-religious group, mostly participants were from joint family system.

Table 2 shows Cronbach alpha reliability of depression, anxiety, stress subscales, Ryff psychological well-being scale and religiosity measure scale on preand post-assessments for the sample. The reliability analysis indicates that the subscales of depression and stress, psychological well-being and religiosity scales

Table 2 Psychometric properties of subscales of depression anxiety stress scale (DASS-21), and psychological well-being scale (PWS-42) $(N=60)$

\begin{tabular}{|c|c|c|c|c|c|c|c|}
\hline \multirow[t]{2}{*}{ Variables } & \multirow[t]{2}{*}{$k$} & \multirow[t]{2}{*}{$a$} & \multirow[t]{2}{*}{$\mathrm{M}(\mathrm{SD})$} & \multicolumn{2}{|l|}{ Range } & \multirow[t]{2}{*}{ Skew } & \multirow[t]{2}{*}{ Kurt } \\
\hline & & & & Potential & Actual & & \\
\hline Pre-test depression & 7 & .65 & $6.51(3.77)$ & $0-21$ & $0-16$ & .42 & -.46 \\
\hline Post-test depression & 7 & .68 & $2.30(2.43)$ & $0-21$ & $0-14$ & .48 & -.58 \\
\hline Pre-test anxiety & 7 & .47 & $6.06(3.10)$ & $0-21$ & $0-14$ & 1.16 & 3.59 \\
\hline Post-test anxiety & 7 & .54 & $2.43(2.54)$ & $0-21$ & $0-10$ & 1.20 & 1.12 \\
\hline Pre-test stress & 7 & .81 & $8.18(4.65)$ & $0-21$ & $2-18$ & .48 & -1.18 \\
\hline Post-test stress & 7 & .73 & $2.85(2.95)$ & $0-21$ & $0-14$ & 1.88 & 2.01 \\
\hline Pre-test PWB & 42 & .87 & $147.41(15.95)$ & $0-252$ & $123-222$ & .17 & -.50 \\
\hline Post-test PWB & 42 & .75 & $171.86(24.38)$ & $0-252$ & $122-211$ & .09 & .57 \\
\hline Religiosity scale & 5 & .78 & $15.08(3.30)$ & $0-25$ & $7-19$ & -.86 & -.17 \\
\hline
\end{tabular}

$M$ Mean, $S D$ standard deviation, $P W B$ psychological well-being 
Table 3 Descriptive statistics and correlation of the study variables for high- and lowreligious levels

\begin{tabular}{|c|c|c|c|c|c|c|}
\hline Variables & $n$ & M & SD & 12 & 3 & 4 \\
\hline \multicolumn{7}{|c|}{ High religiosity group } \\
\hline 1. Depression & 30 & 2.47 & 2.20 & - & & \\
\hline 2. Anxiety & 30 & 2.43 & 2.50 & $-.063 *$ & - & \\
\hline 3. Stress & 30 & 3.13 & 3.30 & -.036 & $0.73 * *$ & - \\
\hline 4. PWB & 30 & 173.87 & 27.35 & -.033 & $.487 * *$ & $.527 * *$ \\
\hline \multicolumn{7}{|c|}{ Low religiosity group } \\
\hline 1. Depression & 30 & 2.13 & 2.67 & - & & \\
\hline 2. Anxiety & 30 & 2.43 & 2.63 & $-.123 *$ & - & \\
\hline 3. Stress & 30 & 2.57 & 2.58 & -.125 & $\mathbf{0 . 8 4 3 * * *}$ & - \\
\hline 4. PWB & 30 & 163.43 & 19.40 & -.182 & $0.368 *$ & $.407^{*}$ \\
\hline
\end{tabular}

${ }^{*} p<0.05, * * p<0.001$

Table 4 Mean, standard deviation and t test values Of depression, anxiety, stress and psychological wellbeing on pre-test and post-test measures $N=(60)$

\begin{tabular}{llllllll}
\hline Variables & Pre-test & Post-test & \multicolumn{2}{l}{$95 \% \mathrm{CI}$} & & & \\
\cline { 4 - 8 } & $\mathrm{M}(\mathrm{SD})$ & $\mathrm{M}(\mathrm{SD})$ & $\mathrm{t}(59)$ & $p$ & $\mathrm{LL}$ & $\mathrm{UL}$ & Cohen's $d$ \\
\hline Depression & $6.51(3.77)$ & $2.30(2.43)$ & 6.60 & .000 & 2.93 & 5.49 & 1.32 \\
Anxiety & $6.06(3.10)$ & $2.43(.54)$ & 6.88 & .000 & 2.57 & 4.68 & 1.28 \\
Stress & $8.18(4.65)$ & $2.85(2.95)$ & 7.29 & .000 & 3.86 & 6.79 & 1.36 \\
PWB & $147.41(15.95)$ & $171.86(24.38)$ & -2.24 & .029 & -22.44 & -1.29 & 0.49 \\
\hline
\end{tabular}

$M$ Mean, $S D$ standard deviation, $C I$ confidence interval, $L L$ lower limit, $U L$ upper limit, $P W B$ psychological well-being scale

are internally consistent as the alpha coefficient reliability of the scales ranges from 0.65 to 0.87 which is satisfactory however, for the subscale of anxiety it is from 0.47 to 0.54 which is below satisfactory level. The skewness and kurtosis of all scales are within the acceptable range.

Table 3 correlation analyses were carried on pre-test assessments of depression, anxiety, stress and psychological well-being scale for high- and low-religious groups to see the group equivalence of the participants across the groups. Results in Table 3 indicate that depression, anxiety and stress are negatively correlated with psychological well-being in both high- and low-religious groups. The negative relationship between psychological well-being and depression is significant. However, for psychological well-being negative correlation is nonsignificant for anxiety and stress at the level of 0.05 . Both groups indicate that there is equivalence in the psychological states for the participants of both groups. This means that when depression, anxiety and stress are poor then psychological well-being is higher. In other words, it could be said that when depression, anxiety and stress are higher, psychological well-being is lower.

Table 4 shows pre- and post-test mean scores, standard deviations and test scores of all the study variables. Paired sample t test reveals that in pre-test to 
Table 5 Descriptive statistics of categories of depression anxiety stress scale (DASS-21), $N=(60)$

\begin{tabular}{|c|c|c|c|c|c|}
\hline & & \multicolumn{2}{|c|}{ Pre-test } & \multicolumn{2}{|c|}{ Post-test } \\
\hline & & $f$ & $\%$ & $f$ & $\%$ \\
\hline \multirow[t]{3}{*}{ Depression } & Normal & 3 & 5.0 & 58 & 96.7 \\
\hline & Mild & 45 & 75.0 & 1 & 1.7 \\
\hline & Moderate & 12 & 20.0 & 1 & 1.7 \\
\hline \multirow[t]{3}{*}{ Anxiety } & Normal & 1 & 1.7 & 57 & 95.0 \\
\hline & Mild & 57 & 95.0 & 1 & 1.7 \\
\hline & Moderate & 2 & 3.3 & 2 & 3.3 \\
\hline \multirow[t]{3}{*}{ Stress } & Normal & 3 & 5.0 & 58 & 96.7 \\
\hline & Mild & 12 & 20.0 & 1 & 1.7 \\
\hline & Moderate & 45 & 75.0 & 1 & 1.7 \\
\hline
\end{tabular}

Table 6 Gender differences on depression, anxiety, stress and psychological well-being on post-test measures $(N=60)$

\begin{tabular}{llllllll}
\hline Variables & Male $(n=23)$ & Female $(n=37)$ & $95 \%$ CI & & & \\
\cline { 5 - 8 } & $\mathrm{M}(\mathrm{SD})$ & $\mathrm{M}(\mathrm{SD})$ & $\mathrm{t}(58)$ & $p$ & $\mathrm{LL}$ & $\mathrm{UL}$ & Cohen's $d$ \\
\hline Depression & $1.52(1.41)$ & $2.78(2.81)$ & -1.99 & .05 & -2.52 & .001 & 0.56 \\
Anxiety & $2.30(2.14)$ & $2.51(2.79)$ & .30 & .76 & -1.57 & 1.15 & 0.08 \\
Stress & $1.73(1.81)$ & $3.54(3.32)$ & -2.38 & .02 & -3.31 & -.288 & 0.67 \\
$\begin{array}{l}\text { Psychological } \\
\text { well-being }\end{array}$ & $149.73(16.60)$ & $145.97(15.58)$ & .88 & .37 & -4.72 & 12.26 & 0.23 \\
\hline
\end{tabular}

post-test, there is significant decrease in scores of depression anxiety and stress, and significant increase in scores of psychological well-being after Islamic patterned art therapy.

Table 5 shows the categories of depression, anxiety and stress based on the severity ranges. This descriptive analysis was carried out to see the changes in the pattern of degree of depression, anxiety and stress across pre-test and post-test assessments. Results indicate that the number of cases from moderate to normal increased in post- to pre-test measurements of the depression anxiety stress scale on the overall sample of the study.

Table 6 shows the results of independent sample $t$ test for the comparison of male and female participants on post-assessment for study variables. Results indicate that there is no significant difference between the mean scores of male and female participants on anxiety and psychological well-being, whereas depression is not significant; its $p$ value is not less than 0.05 . There is nonsignificant difference between the mean scores on depression and stress.

The Table 7 indicates there was a significant main effect of art therapy on depression of the participants $\mathrm{F}(1,58)=43.016, p<0.001, n^{2} p=0.43$; however, the interaction between depression and religiosity, $\mathrm{F}(1,58)=0.15, p=0.69, n^{2} p=0.003$ was nonsignificant. The between-subject differences indicate that the differences on the two groups i.e. low religiosity and high religiosity, were not significant. The main 
Table 7 Repeated measures ANOVA for within group and between group comparisons for depression

\begin{tabular}{lllllll}
\hline Effect & MS & Df & F & $p$ & $\begin{array}{l}\text { Greenhouse- } \\
\text { Geisser }\end{array}$ & Huynh-Feldt \\
\hline $\begin{array}{l}\text { Within-subject factors } \\
\text { Depression }\end{array}$ & 533.408 & 1 & 43.016 & .000 & $<.001$ & $<.001$ \\
$\begin{array}{l}\text { Depression x religiosity } \\
\text { Between-subject factors }\end{array}$ & 1.875 & 1 & .151 & .699 & $<.01$ & $<.01$ \\
Intercept & 2332.008 & 1 & 286.388 & .000 & $<.001$ & $<.001$ \\
Religiosity & .208 & 1 & .026 & .873 & $<.01$ & $<.01$ \\
\hline
\end{tabular}

effect of religiosity was nonsignificant, $\mathrm{F}(1,58)=0.26, p=0.87, n^{2} p=0.000$, thus failing to prove that the effect of depression and religiosity was different for high and low levels of religiosity.

The Table 8 indicates that there was a significant main effect of art therapy on anxiety of participants, $\mathrm{F}(1,58)=47.32, p<0.001, n^{2} p=0.45$ However, the interaction between anxiety and religiosity, $\mathrm{F}(1,58)=0.97, p=0.330, n^{2} p=0.016$, was nonsignificant. The between-subject differences indicate that the differences on the two groups, i.e., low religiosity and high religiosity were nonsignificant, F (1, $58)=0.896, p=0.348, n^{2} p=0.015$, thus failing to prove that the effect of anxiety and religiosity was different for high and low levels of religiosity.

The Table 9 indicates that there was a significant main effect of art therapy on stress of participants, $\mathrm{F}(1,58)=52.29, p<0.001, n^{2} p=0.48$. However, the interaction between stress and religiosity, $\mathrm{F}(1,58)=0.516, p=0.475, n^{2} p=0.009$, was nonsignificant. The between-subject differences indicate that the differences on the two groups, i.e., low religiosity and high religiosity were nonsignificant. The main effect of religiosity was nonsignificant, $\mathrm{F}(1,58)=0.008, p=0.93, n^{2} p=0.000$, thus failing to prove that the effect of stress and religiosity was different for high and low levels of religiosity.

The Table 10 indicates that there was a significant main effect of art therapy on psychological well-being of participants, $\mathrm{F}(1,58)=38.73, p<0.001, n^{2} p=0.400$. However, the interaction between psychological well-being and religiosity, F (1, $58)=0.310, p=0.60, n^{2} p=0.005$, was nonsignificant. The between-subject differences indicate that the differences on the two groups, i.e., low religiosity and

Table 8 Repeated measures ANOVA for within group and between group comparisons for anxiety

\begin{tabular}{|c|c|c|c|c|c|c|}
\hline Effect & MS & Df & $\mathrm{F}$ & $p$ & $\begin{array}{l}\text { Greenhouse- } \\
\text { Geisser }\end{array}$ & Huynh-Feldt \\
\hline \multicolumn{7}{|l|}{ Within-subject factors } \\
\hline Anxiety & 396.033 & 1 & 47.315 & .000 & $<.001$ & $<.001$ \\
\hline Anxiety $\mathrm{x}$ religiosity & 7.500 & 1 & .896 & .348 & $<.01$ & $<.01$ \\
\hline \multicolumn{7}{|c|}{ Between-subject factors } \\
\hline Intercept & 2167.500 & 1 & 279.367 & .000 & $<.001$ & $<.001$ \\
\hline Religiosity & 7.500 & 1 & .967 & .330 & $<.01$ & $<.01$ \\
\hline
\end{tabular}


Table 9 Repeated measures ANOVA for within group and between group comparisons for stress

\begin{tabular}{lllllll}
\hline Effect & MS & Df & F & $p$ & Greenhouse-Geisser & Huynh-Feldt \\
\hline Within-subject factors & & & & & & \\
Stress & 853.333 & 1 & 52.289 & .000 & $<.001$ & $<.001$ \\
$\begin{array}{l}\text { Stress x religiosity } \\
\text { Between-subject factors }\end{array}$ & 133 & 1 & .008 & .928 & $<.01$ & $<.01$ \\
Effect & MS & Df & F & $p$ & Greenhouse-Geisser & Huynh-Feldt \\
Intercept & 3652.033 & 1 & 252.426 & .000 & $<.001$ & $<.001$ \\
Religiosity & 7.500 & 1 & .516 & .475 & $<.01$ & $<.01$ \\
\hline
\end{tabular}

Table 10 Repeated measures ANOVA for within group and between group comparisons for psychological well-being

\begin{tabular}{lllllll}
\hline Effect & MS & Df & F & $p$ & $\begin{array}{l}\text { Greenhouse- } \\
\text { Geisser }\end{array}$ & Huynh-Feldt \\
\hline $\begin{array}{l}\text { Within-subject factors } \\
\text { PWB }\end{array}$ & $17,934.075$ & 1 & 38.727 & .000 & $<.001$ & $<.001$ \\
PWB x religiosity & 279.075 & 1 & .603 & .441 & $<.01$ & $<.01$ \\
$\begin{array}{l}\text { Between-subject factors } \\
\text { Intercept }\end{array}$ & $3,058,255.408$ & 1 & 7767.140 & .000 & $<.001$ & $<.001$ \\
Religiosity & 122.008 & 1 & .310 & .580 & $<.01$ & $<.01$ \\
\hline
\end{tabular}

high religiosity were nonsignificant. The main effect of religiosity was nonsignificant, $\mathrm{F}(1,58)=0.603, p=0.441, n^{2} p=0.010$, thus failing to prove that the effect of psychological well-being and religiosity was different for high and low levels of religiosity.

\section{Qualitative/Content Analysis}

For qualitative analysis, content analysis was carried out for usage of color, line quality for coloring, time taken for coloring designs and interpretation of calligraphy experience. The results of the content analysis may provide a better picture of the experience of the participants and effect of coloring on their psychological states.

\section{Color Usage}

The colored art designs by the participants of the study were analyzed qualitatively as well through content analysis. The analysis of color usage interpretation criteria by Malchiodi (2007) was used. A set of 12 colors was provided in a pencil color box to each participant. Use of specific color or variety of colors or lack of colors is also significant for interpretation. However, for the present study an overall analysis was conducted for the group of participants keeping a focus on use of specific colors and 
their possible meaning. The overall analysis of color usage reveals that on average most of the participants used black and red colors in the initial 4-5 sessions, and then, a change in the selection of colors was observed in the coloring patterns of the participants. Afterward, there was more usage of yellow, blue and green colors, and till the last session, more vibrant colors like blue, orange green, purple and yellow were used indicating warmth, energy, wisdom, creativity, growth, imagination, spirituality, relaxation and calmness.

\section{Reaction Time, Time Taken and Attitude of the Subject Toward the Task}

For the present study, reaction time was defined as interval of time measured in seconds between presentation of the art designs given to color and voluntary response of the participant to indulge in coloring activity (selecting, picking pencil color and initiate color filling). This was further assessed to tap the attitude of the subject toward the coloring task. After receiving instructions if subject does not begin coloring within $30 \mathrm{~s}$, indicated conflict (Buck, 1966). However, all the subjects took less than $30 \mathrm{~s}$ to begin coloring.

The reaction time ranged from 0 to $30 \mathrm{~s}$ with a Mean of $6.36 \mathrm{~s}$. No problematic delays in responding were observed. Time taken for coloring a design was specified as $30 \mathrm{~min}$ for each session. Total time taken for each design was also noted. The total time to color a design ranged from 0 to $30 \mathrm{~min}$, and for all the subjects of the study, the mean for total time was found to be $9.67 \mathrm{~min}$.

All the subjects of the study were willing to proceed with the coloring therapy and accepted the tasks happily, and it was observed that they had no difficulty in selection of colors or in actual performance of coloring of all selected designs (by their choice) and their specific details which indicated that all the subjects had no organicity, suspiciousness, conflict, frustration or maladjustment. And there were no observations of verbal criticism or abandonment of a design to color, indicating that there were no signs of conflict (Buck, 1966). Because every subject already had a choice to select a design as per their priority to color, they did not abandon any design or criticized.

\section{Line Quality}

The line quality of coloring was assessed via criteria set by Cole (2003). It was observed while interpreting the coloring art designs of the participants that most of the participants used well-controlled and free flowing strokes of the color pencils on the designs being colored, indicating that subjects had no motor impairment and had good adjustment. However, some of the participants on average till 4-5 sessions used heavy lines for specific details which may be interpreted as trends of forcefulness, hostility and fixation. While others showed faint lines that were used throughout by few of the subjects, indicating that there was reluctance of expression in them. These findings about the usage of faint lines may be interpreted as indication of lack of energy, depression, insecurity, inhibition or shyness. Some drawings also indicated a bit of usage of shading which may be considered as presence of 
mild or moderate anxiety (Buck, 1966). There were no cross-hatching, jagging or use of eraser observed.

\section{Calligraphy Interpretation}

The intervention of color therapy was planned to end with free-hand calligraphy in the last session being a tool for relaxation. It was interpreted in terms of the subjective report taken by the participants. After creating or writing calligraphy, a subjective report was taken from the participants. The content analysis of the subjective reports indicated that most of the study participants gave an acknowledgement that they felt relaxed, calmed, stress free an above all most of the participants reported that they felt joyous to be able to create/write something Holy with their hands and considered it as a blessing from Allah. Some reported that calligraphy was stress-relieving, reduced their anxiety and felt the same way as if they have done meditation.

\section{Discussion}

The present study applied an Islamic integrated art therapy intervention to students with mild to moderate degree of depression, anxiety and stress. The point of the ponder was to discover out the efficacy of Adult Islamic coloring book in reducing psychological issues like depression anxiety stress and enhancement of psychological well-being by comparing the levels of religiosity of the study sample which were university students. University students have to go through every day stressors all through their scholarly careers which can have enduring results to their health and well-being. A study conducted on university students in Florida state university USA revealed that art therapy helped in the significant decrease of the symptoms of anxiety and not in the level of stress (Beerse et al. 2019). Comes about of the ponder shown that from pre-test to post-test measures, it was evidenced that this therapy was found effective for the decline in depression, anxiety, stress and increase in psychological well-being of the sample of the university students.

Review of the literature revealed that previous art-based intervention studies such as Sandmire et al. 2012; Mehmood et al. 2017; Chapman et al. 2011; Gussak, 2007; Lisa \& Myrna, 1997; Boucher, 2016 also found that the similar results showed decrease in depression, anxiety and stress. Present study also showed similar results that after using Islamic adult coloring book the degree of depression, anxiety and stress were significantly decreased after comparing pre- and post-test assessments.

Art therapy is effective for both males and females and it were hypothesized that there will be notable gender differences on post-test measures of depression, anxiety stress and also psychological well-being. Sexual orientation is one of the basic determinants of well-being which impacts the control men and women have over the determinants of their health, counting their socioeconomic position, roles, rank, social status, access to resources and treatment in a society. The present study results showed that males and females indicated nonsignificant differences on the means 
scores on depression, anxiety, levels of stress and psychological well-being. And no differences indicate that therapy was equally effective for both males and females.

Religiosity and psychological well-being on gender have significance when considering depression. A study reported that there is a significant change in the domains of psychological well-being of men and ladies on the basis of their devout orientation (Lisa \& Myrna, 1997). In another study, it is mentioned that there is negative association between religiosity and depressive symptoms (Tran et al. 2012). So it can be stated that high religiosity is negatively related with depression, anxiety and stress. Religiosity is a complex term and it cannot be measured with a psychometric tool properly because its multi-dimensional. The outcome of the present study indicated no significant differences on the levels of religiosity on post-test assessments; hence, it could be said that it was found equally effective for both groups, i.e., high- and low-religious groups. Subjects were not informed about the designs or art patterns origin, to not to bias them if they knew that might have an impact on their performance on religiosity scale.

Assessment of the literature revealed that psychological well-being is determined by multiple factors. So it can be stated that it is influenced by more than one factor. Financial status, gender, age, marital status, number of children and qualification are the factors that have a powerful influence on psychological well-being of individuals (Mustafa and Youssof 2018). So the notion could be supported by the above study that as in the present study psychological well-being was increased with Islamic adult coloring book because it decreased the levels of other psychological issues along with its enhancement.

The colored art designs by the participants of the study were analyzed qualitatively as well. The analysis of color usage interpretation criteria by Malchiodi (2007) was used. All colors represent something which needs to be interpreted, and the amount of colors available to participants during the drawing activity is significant.

Therefore, all 12 colors were provided in a pencil color box to each participant. Use of specific color or variety of colors or lack of colors is also significant for interpretation. However, for the present study an overall analysis was conducted for the group of participants keeping a focus on use of specific colors and their possible meaning. The overall analysis of color usage reveals that on average most of the participants used black and red colors in the initial 4-5 sessions, and then, a change in the selection of colors was observed in the coloring patterns of the participants. There was more usage of yellow, blue and green colors, and till the last session, more vibrant colors like blue, orange green, purple and yellow were used indicating warmth, energy, wisdom, creativity, growth, imagination, spirituality, relaxation and calmness (Malchiodi 2007). It can be concluded on the bases of the color usage that as the color therapy proceeded it brought relaxation, creativity and calmness in the minds of the study participants. It could be reported that according to chromatic interpretation of house tree person (HTP) initially study subjects used black which means they were color-shy or anxious and as the therapy proceeded they used many colors showing that they were highly emotional with their expression (Buck, 1966).

For every external stimulus, there is a purposeful voluntary response termed as reaction. The specific time duration between the application of the external stimulus and appropriate motor response to that stimulus is called reaction time (Batra et al. 
2014). In other words, it is the time interval between the presentation of stimulus and the proper voluntary response of a subject (Balakrishnan et al. 2013).

Reaction time is usually demonstrated in milliseconds. It is dependent on the action of sensory system which includes neurological, cognitive domains and how information is processed (Mohan et al. 1984). After receiving information (visual or auditory), its processing, decision making and giving the response or motor act are the processes which follow one another and this is what is called reaction time (Baayen and Milin 2010).

For the present study, reaction time was elucidated as interval of time measured in seconds between presentation of the art designs given to color and voluntary response of the participant to indulge in coloring activity (selecting, picking pencil color and initiate color filling). This was further assessed to tap the attitude of the subject toward the coloring task. After receiving instructions if subject does not begin coloring within $30 \mathrm{~s}$, indicated conflict (Buck, 1966). However, all the subjects took less than $30 \mathrm{~s}$ to begin coloring.

The reaction time ranged from 0 to $30 \mathrm{~s}$ with a mean of $6.36 \mathrm{~s}$. No problematic delays in responding were observed. Time taken for coloring a design was specified as $30 \mathrm{~min}$ for each session. The total time to color a design ranged from 0 to $30 \mathrm{~min}$, and for all the subjects of the study, the mean of $9.67 \mathrm{~min}$ was found.

All the subjects of the study were willing to proceed with the coloring therapy and accepted the tasks happily and it was observed that they had no difficulty in selection of colors or in actual performance of coloring of all selected designs (by their choice) and their specific details which indicated that all the subjects had no organicity, suspiciousness, conflict, frustration or maladjustment. And there were no observations of verbal criticism or abandonment of a design to color, indicating that there was no signs of conflict (Buck, 1966). Because every subject already had a choice to select a design as per their priority to color, they did not abandon any design or criticized.

Age is very significant when observing reaction time. The difficult limit for human response speed is around $200 \mathrm{~ms}$ in a purge circumstance. In the event that you are seeking out for a particular thing, you are very well-conditioned, but it may happen at any time, so you are going to respond to it around $200 \mathrm{~ms}$ or slower on the normal. Presently, $200 \mathrm{~ms}$ is superhumanly fast. The fastest possible conscious human reactions are around $0.15 \mathrm{~s}$, but most are around $0.2 \mathrm{~s}$. There is a difference on the type of stimulus when calculating reaction time. For an average human, the reaction time for visual stimulus is $0.25 \mathrm{~s}, 0.17$ for an audio stimulus and for touch stimulus it is $0.15 \mathrm{~s}$. In a study conducted by Pachella in 1973, it is stated that the overall average for the 4-13 age groups was $0.013 \mathrm{~s}$ less than the overall average for the 14-24 age group. The 14-24 age groups at an average were second fastest of all the age groups. These findings show that age must be considered before calculating or measuring reaction time. The age range in the present study was 18-30 years so in accordance with the above-mentioned research it could be concluded that as the stimulus was visual/touch and the age was adults so the reaction time is a bit higher.

It was observed while interpreting the coloring art designs of the participants that most of the participants used well-controlled and free flowing strokes of the color pencils on the designs being colored, indicating that subjects had no 
motor impairment and had good adjustment. However, some of the participants on average till 4-5 sessions used heavy lines for specific details which may be interpreted as trends of forcefulness, hostility and fixation (Coles, 2003). While others showed faint lines that were used throughout by few of the subjects indicating that there was reluctance of expression in them. These findings about the usage of faint lines may be interpreted as indication of lack of energy, depression, insecurity, inhibition or shyness (Coles, 2003). Some drawings also indicated a bit of usage of shading which may be considered as presence of mild or moderate anxiety (Buck, 1966). There were no cross-hatching, jagging or use of eraser observed.

Calligraphy is a way of expressing one's inner self. Calligraphy is a practice of meditation (Kao, 2010). The intervention of color therapy was planned to be ended with free-hand calligraphy in the last session as calligraphy is a medium used for relaxation (Kao et al. 2014). For this purpose a black chisel tip marker was provided to the subjects. After creating or writing calligraphy, a subjective report was taken from the participants. The reports indicated that most of the study participants gave an acknowledged that they felt relaxed, calmed, stress free an above all most of the participants reported that they felt joyous to be able to create/write something Holy with their hands and considered it as a blessing from Allah. Some reported that calligraphy was stress-relieving, reduced their anxiety and felt the same way as if they have done meditation.

A study conducted on cancer patients in china revealed that Chinese calligraphy handwriting showed similar results with effects of relaxation, improved mood and heightened concentration improving the health of the patents in general (Yang et al. 2010).

Arabic calligraphy is not just taught in Muslim countries but also in renowned universities of the west as well. A well-known Palestinian artist Majed Abu Ajameyeh is currently teaching calligraphy in Loyola university Chicago and is conducting numerous special calligraphy workshops with students from different regions and religions and they reported that calligraphy is of great significance for the improvement of their overall health and outlook about Arabic calligraphy (Sabbadi, 2018).

In order to assess the effectiveness of the treatment modalities, a follow-up was conducted after three months, yet, due to non-availability of the participants due to Pandemic of Covid-19, the follow-up was conducted in the form of a feedback in order of obtaining the data on the psychological status of the participants. Some of the participants were not accessible; therefore, only $63 \%$ of the data was accessed and a feedback as verbatim was taken.

The present studies figured out that the Islamic integrated art therapy has rendered a better psychological health for the sample. There are many therapies that are found to be effective for the reduction of depression anxiety and stress and enhancement of psychological well-being. However researcher focused on a distinctive strategy, that with the help of Islamic adult coloring book one can learn this technique as self-help and could be used anytime when encountered in future with any psychological issue. 


\section{Limitations}

- One of the limitations of this study is the small test sample since of which comes about cannot be generalized to other than the participants.

- The reliability analysis of the present study showed that the reliability of anxiety was not satisfactory or below satisfactory level after pre- and post-test assessment of depression anxiety and stress scale. This might be due to sample size, if sample size was larger, probably the subscale would have reached a satisfactory level of reliability.

- In order to assess the effectiveness of the treatment modalities, a follow-up was conducted. Yet, due to non-availability of the participants due to Pandemic of Covid-19, the follow-up was conducted in the form of a feedback in order of obtaining the data on the psychological status of the participants. Some of the participants were not accessible; therefore, only $63 \%$ of the data was accessed and a feedback as verbatim was taken.

- Religiosity is a complex phenomenon that cannot be simply measured in terms of psychometric tool. Therefore, in future more ways of assessments may be used, for example, interview.

- Content analysis takes after an orderly strategy that can effectively be reproduced by other researchers, yielding comes about with high reliability. Content analysis involves some degrees of subjective interpretation, which may have affected the unwavering quality and legitimacy of the outcomes about and conclusions.

\section{Suggestions and Recommendations}

- The strength of the present study is that it is developed by the researcher so it is something very new and interesting and would urge other to do this Islamic adult coloring book with other variables as well.

- It is suggested that mediums other than pencil colors could be used with handicapped and illiterate for psychological and physiological health improvement.

- The conditions of the room in which the therapy was conducted were regulated in order for the subject to feel comfortable while coloring Islamic adult coloring book. The environment of the room was free from distractions, and all the phones were put on silent. The seating was also comfortable enough for the subject to do color. Last but not the least, the room was well-lit and had moderate temperature. But still all the conditions could not be controlled, so it is better to do this therapy in experimental laboratory where all external conditions could be controlled.

- Current study included one intervener connection with both bunches. This investigated plan has the quality within the comparability of therapist's com- 
mon characteristics in both bunches and over all the participants (Wampold 2001). In any case, the outcomes about for the two bunches may have been partially due to an "experimenter effect" (Wampold 2001). Nevertheless, Islamic coordinates craftsmanship treatment is distinctive from other forms of interpersonal therapies because it centers more on individual preferences and not one-sided by experimenter effect (Lee and Enright's 2014).

- Reaction time could be a degree of how rapidly an organism can react to a specific stimulus. Numerous variables have been appeared to influence reaction times, counting age, sex, physical wellness, fatigue, diversion, liquor, identity type, and whether the stimulus is sound-related or visual. However, these were not controlled or assessed (Thombre et al. 1984).

- Measures were taken to control the biases in the research. Pre-trial bias was controlled by setting inclusion/exclusion criteria and by controlled randomization of participants through an unbiased research assistant. Interviewer bias was controlled by getting the pre-assessment of participants done by some other member (Research Assistant) not by examiner. Performance bias was controlled by following the pre-defined protocol of therapy for all participants. Post-trial bias was controlled by getting the post-assessment of participants done by some other member not by examiner.

- Previously no such work was done so it is quite unique and one of its first kinds, especially keeping in mind the concept on aniconism in consideration it was developed.

- Researchers and clinicians can test whether the Islamic integrated art therapy may also be helpful with clients and normal population with other variables and to enhance their psychological and physiological health and its effectiveness in general.

- Similarly, future studies can investigate the viability of this therapy with regard to particular sort of disorder other than depression or anxiety while adding more demographic variables such as personality type and economic status so that a genuine experimental study may be designed.

- If test estimate/sample size was huge there may well be a factually critical contrast in viability of therapy with regard to sex and marital status, diverse age groups so future studies should be carried out with large sample size.

- It is suggested that future researches should differentiate the Islamic integrated art therapy with conventional art therapy to study its effectiveness in Muslim population.

\section{Implications}

Clinicians may be able to assist clients and general population to use Islamic adult coloring book which can empower them to change their negative mental and physiological reactions in to versatile and solid ones. Such changes can play a part in adapting with the sickness and creating strength and flexibility. This therapy might 
moreover abdicate positive psychological as well as physical health results in patients and general population.

Islamic integrated art therapy can be utilized by educationists as a part of the preparing manuals for students in arrange to progress the physical as well as mental health of this populace. Additionally social psychologists, family or couple advisors may utilize Islamic integrated art therapy with their clients in arrange to smoothen interpersonal troubles in their personal, occupational and academic life.

Being an Islamic integrated art therapy, it can be best for use by the clinical analyst as well as clients with devout or spiritual inclination. Pakistan is an Islamic state and majority of the people here are against aniconism, i.e., prohibition of humanly/ alive figures so to overcome their life stressors, that could be personal, social, academic or occupational, one can self-help with that through this therapy. And colors have strong impact on human physique so it freshens up the mood and bring positivity and improves psychological and physiological well-being.

\section{Conclusion}

Students face many stressors like social, personal and academic. To deal with them with the help of art and shapes of Islamic origin, this Islamic integrated art therapy was developed. Present study participants subjectively reported that after coloring Islamic adult coloring book, they felt relaxed, calmed and better mood. Quantitative and qualitative results indicate that this therapy was found effective in reduction of depression, anxiety and stress and improved mood. This Islamic integrated art therapy could be used as a self-help technique in future. This Islamic adult coloring book is not only beneficial for university students, rather it could be used with different populations like patients and general population to find its effectiveness.

\section{Declarations}

Conflict of interest All authors declare that they have conflict of interest.

Ethical standards All APA ethical standards were followed for the present research.

\section{References}

Anil, M. (2012). Measurement and meaning of religiosity: a cross-cultural comparison of religiosity and charitable giving. Journal of Targeting, Measurement And Analysis for Marketing., 20, 84-95.

Baayen, R. H., \& Milin, P. (2010). Analyzing reaction times. International Journal of Psychological Research, 3(2), 12-28.

Balakrishnan, G., Uppinakudru, G., Girwar Singh, G., Bangera, S., Dutt Raghavendra, A., \& Thangavel, D. (2014). A comparative study on visual choice reaction time for different colors in females. Neurology Research International. https://doi.org/10.1155/2014/301473 .

Batra, A., Vyas, S., Gupta, J., Gupta, K., \& Hada, R. (2014). A comparative study between young and elderly indian males on audio-visual reaction time. Indian Journal of Scientific Research and Technology, 2(1), 25-29. 
Beerse, M. E., Lith, V. T., Gregg, D., \& Stanwood, D. G. (2019). Is there a biofeedback response to art therapy? A technology-assisted approach for reducing anxiety and stress in college students. Journals SAGE Open., 9, 2158. https://doi.org/10.1177/2158244019854646.

Bosch, K. G. (2015). Islamic art and architecture. Retrieved from http://www.scholastic.com/browse/ article.jsp?id=3753881

Boucher, B. (2016). There's proof that making art can actually reduce stress. Retrieved from http://www. businessinsider.com/theres-proof-that-making-art-can-reduce-stress-2016-6

Buck, J. N. (1966). The House Tree Person Technique, revised manual western psychological services California

Cohen, A. B., \& Koenig, H. G. (2003). Religion, religiosity and spirituality in the biopsychosocial model of health and ageing. Ageing international, 28(3), 215-241.

Coles, J. (2003). Signals from the Child: Learn to Read the Secrets in Drawings and Refrigerator Art. Emba House Llc.

Chapman, L., Morabito, D., Ladakakos, S., \& H., \& Knudon, M. M. (2011). The effectiveness of art therapy interventions in reducing post traumatic stress disorder (PTSD) symptoms in pediatric trauma patients. Art Therapy, 18(2), 100-104. https://doi.org/10.1080/07421656.2001.10129750.

Gussak, D. (2007). The effectiveness of Art Therapy in Reducing Depression in Prison populations. International Journal of Offender Therapy and Comparative Criminology. https://doi.org/10.1177/ $0306624 X 06294137$.

Henry, R. (2015). A Review of "Islamic geometric design. Oxfordshire: Taylor and Francis.

Holmqvist, L., Jormfel, H., Larsson, I., \& Persson, L. C. (2016). Women's experiences of change through art therapy. Arts and Health, 9(3), 199-212. https://doi.org/10.1080/17533015.2016.1225760.

Ho, D., \& F. \& Ho, H., R. (2007). Measuring spirituality and spiritual emptiness: Toward ecumenicity and transcultural applicability. Review of General Psychology., 11(1), 62-74. https://doi.org/10. 1037/1089-2680.11.1.62.

Hunt, J., \& Eisenberg, D. (2010). Mental health problems and help-seeking behavior among college students. Journal of Adolescent health, 46, 3-10.

Hussain, B., Khalily, M. T. (2015). The role of art in the amelioration of mental health problems: Vignettes from Pakistan. World Cultural Psychiatric Research Review, 242-248.

Jeff, P., Murray, D., \& Paul, B. (2010). Depression anxiety stress scale: Is it valid for children and adolescents? Journal of clinical psychology, 66(9), 996-1007. https://doi.org/10.1002/jclp.20696.

Kao, H. S., Zhu, L., Chao, A. A., Chen, H. Y., Liu, I. C., \& Zhang, M. (2014). Calligraphy and meditation for stress reduction: an experimental comparison. Psychology research and behavior management, $7,47$.

Kao, H. S. (2010). Calligraphy therapy: A complementary approach to psychotherapy. Asia Pacific Journal of Counselling and Psychotherapy, 1(1), 55-66.

Khan, T. (2012). Musings on the impact of aniconism and the practice of art therapy within a Muslim community. Art Therapy Online, 3(1)

Lisa, M., \& Myrna, W. (1997). Religiosity and depression: Ten year follow-up of depressed mothers and offspring. Journal of the American academy of child and adolescent psychiatry, 36(10), 1416-1425.

Lovibond, P. F., \& Lovibond, S. H. (1995). The structure of negative emotional states: comparison of the depression anxiety stress scales (DASS) with the beck depression and anxiety inventories. Behaviour Research and Therapy, 33(3), 335-343.

Malchiodi, A. C. (2003). Handbook of art therapy. New York: Guil Ford Publications.

Malchiodi, A. C. (2007). Art therapy sourcebook. New York: McGraw Hill Professional.

Mehmood, N. S., Saleem, T., Azmat, J., \& Arouj, K. (2017). Mandala Coloring as a therapeutic intervention for anxiety reduction in university students. Pak Armed Forces Medical Journal, 67(6), 904-907.

Michael, A., Hayes, C., \& Cowie, H. (2007). Psychology and religion: mapping the relationship. Mental health religion and culture., 8(1), 27-33.

Mohan, M., Thombre, D. P., Das, A. K., Subramanian, N., \& Chandrasekar, S. (1984). Reaction time in clinical diabetes mellitus. Indian Journal of Physiology and Pharmacology, 28(4), 311-314.

Modudi, A. A. (1983). Tafheem Ul Qur'an. (p. 182). Lahore: Wafaq printing Press.

Mounsey, D., \& Vandehey \& Diekhoff. (2013). Working and non-working students: Anxiety, depression and grade average. College Student Journal., 47, 2.

Mustafa., B. A., Youssof., O., (2018). Factors affecting psychological well-being: Evidence from two nationally representative surveys. Retrieved from https://www.researchgate.net/publication/32575 
2724_Factors_affecting_psychological_well-being_Evidence_from_two_nationally_representative_ surveys.

Olesen, J. (2018). Therapeutic benefits of coloring books for adults. Retrieved from http://www.colormeanings.com/10-therapuetic-benefits-of-coloring-books-for-adults/

Pachella, R. G. (1973). The interpretation of reaction time in information processing research (No. TR-45). Michigan Univ Ann Arbor Human Performance Center.

Pifalo, T. (2006). Art therapy with sexually abused children and adolescents; extended research study. Journal of the American Art therapy Association, 23(4), 181-185.

Ryff, C., \& Keyes, C. (1995). The structure of psychological well-being revisited. Journal of personality and social psychology, 69, 719-727.

Sabbadi, K. (2018).Arabic Calligraphy: "Therapeutic and Mesmerizing”. Retrieved from http://blogs.luc. edu/student-voices/2018/04/06/arabic-calligraphy-therapeutic-mesmerizing/

Sandmire, D. A., Sarah, R. G., Nancy, E. R., David, R., \& G. (2012). The influence of art making on anxiety: A pilot study. American Psychiatric Association, 29(2), 68-73.

Soganci, I. O. (2004). Islamic aniconism: Making sense of a Messay Literature. Marilyn Zurmuehlen working paper in Art Education. https://doi.org/10.17077/2326-7070.1376.

Tran, C. T., Kuhn, E., Walser, R. D., \& Drescher, K. D. (2012). The relationship between religiosity, PTSD, and depressive symptoms in veterans in PTSD residential treatment. Journal of Psychology and Theology, 40(4), 313-322.

Wampold, B. E. (2001). The great psychotherapy debate. Mahwah, NJ: Erlbaum.

Yang, X. L., Li, H. H., Hong, M. H., \& Kao, H. S. (2010). The effects of Chinese calligraphy handwriting and relaxation training in Chinese Nasopharyngeal Carcinoma patients: A randomized controlled trial. International Journal of Nursing Studies, 47(5), 550-559.

Wilkes, R. E., Burntt, J. J., \& Howell, R. D. (1986). On the meaning and measurement of religiosity in consumer research. Journal of the academy of marketing science, 14, 47-56.

Publisher's Note Springer Nature remains neutral with regard to jurisdictional claims in published maps and institutional affiliations. 